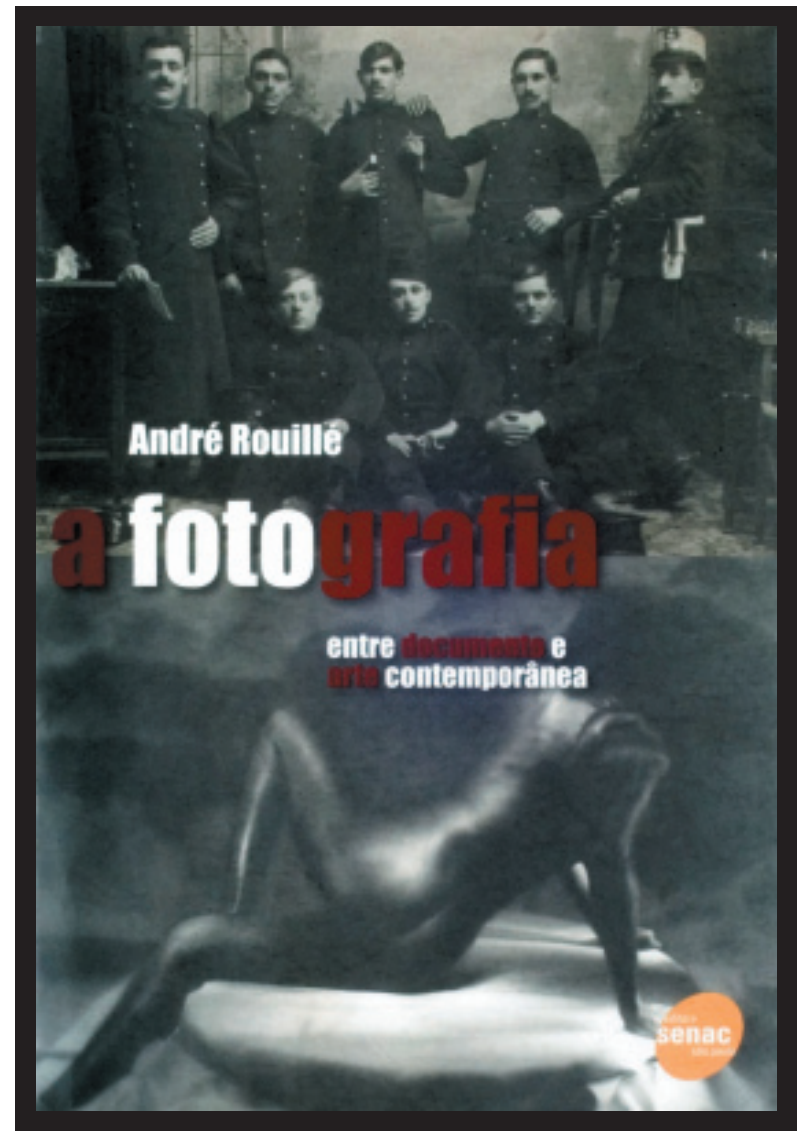

A fotografia - entre documento e arte contemporânea, de André Rouillé.

Tradução de Constancia Egrejas. São Paulo: Senac, 2009, 483 p. 


\title{
Do daguerreótipo à imagem digital: pela ontologia da imagem fotográfica
}

\author{
MariaLuisa Hoffmann*
}

Publicado na França em 2005 e lançado no Brasil em 2009, o livro A fotografia - entre documento e arte contemporânea é resultado de uma ampla pesquisa de André Rouillé, um dos mais importantes críticos de arte franceses. Rouillé é historiador, professor da universidade Paris 8 e diretor do site www.paris-art.com. Em seu texto, dividido em três partes, discorre sobre a fotografia desde sua invenção até o advento da imagem digital e sua recente apropriação pela arte contemporânea. Contraditoriamente, as quase 500 páginas da obra surpreendem por não apresentarem nenhuma fotografia ou imagem de artistas por ele citados.

Rouillé traça um panorama da mudança ontológica da imagem fotográfica e relata que, no plano teórico e das pesquisas, a fotografia é um objeto novo, muitas vezes subestimado ou ignorado. A ambição de seu ensaio é contribuir "para recolocar a fotografia pelo lado direito [...] traçar novas direções, experimentar novas ferramentas teóricas, a fim de evitar que a cultura fotográfica prospere sobre um imenso vácuo de ideias". (ROUILLÉ, 2009, p.17).

Na primeira parte do livro - intitulada Entre documento $e$ expressão, o pesquisador relata que a fotografia apareceu com a sociedade industrial e lhe serviu de ferramenta para atualizar seus valores. O status de veracidade atribuído a essas imagens respondia à necessidade de uma sociedade positivista e racional. Rouillé (2009, p.19) relaciona o surgimento e os diferentes usos da imagem fotográfica aos seus respectivos tempos sócio-históricos e culturais, e afirma que o valor documental, "após ter conhecido níveis elevados na fase

\footnotetext{
*Graduada em Comunicação - Habilitação Jornalismo, pela Universidade Estadual de Londrina. Mestranda em Comunicação pela mesma instituição. Bolsista da Capes.
} 
próspera da sociedade industrial, declina junto com ela, razão pela qual a perda de hegemonia da fotografia-documento abre caminho para outras práticas", como a fotografia-expressão. Até então a utilidade prevalecia sobre a estética e a beleza era facultativa. $\mathrm{O}$ autor admite que as imagens possam ter valor documental, mas defende sua autonomia perante seus referentes e critica a fotografia-documento: a imagem não apenas mostra o real, mas também o cria.

A autoria e a subjetividade ganham espaço na fotografiaexpressão e na crise do documento. A imagem fotográfica passa por profundas mudanças, tanto nos procedimentos como no critério de verdade. "A diferença entre documento e expressão está na essência, não no grau.” (ROUILLÉ, 2009, p.20). A fotografia-expressão é aquela que apresenta, não representa, e a onipresença do sujeito criador se opõe à rejeição da individualidade da fotografia-documento. "A passagem do documento-designação para documento-expressão repercute na fotografia como um fenômeno mais global: [...] a passagem de uma sociedade industrial para uma sociedade da informação." (ROUILLÉ, 2009, p.137).

O autor ressalta que a verdade do documento não é a verdade da expressão e critica o "isso foi" barthesiano, a teoria do índice e seus pensadores - como Dubois - que acreditam que a fotografia é essencialmente representativa. Essas teorias mutilam a fotografia ao vê-la somente pela metade e, de acordo com Rouillé, a imagem fotográfica não é um registro passivo de um referente material que adere, mas produto estético de um evento. No advento da expressão, ainda segundo o autor, o contato direto com o real se tornou supérfluo e a fotografia passou a ser mais conotativa. Rouillé aponta que talvez seja na publicidade e na moda, que a passagem do documento para a expressão tenha atingido sua maior expansão.

$\mathrm{Na}$ segunda parte do livro, Entre fotografia e arte, o autor diferencia a concepção da arte dos fotógrafos e a fotografia dos artistas. Para ele, ambos partem de premissas distintas: enquanto o artista está no campo da arte, o fotógrafo pertence ao campo da 
fotografia, é fotógrafo antes de ser artista. "Os fotógrafos e os fotógrafos-artistas pertencem ao mesmo mundo e frequentemente se misturam." (ROUILLÉ, 2009, p.235).

É possível notar atualmente no fotojornalismo que, ainda que exista a crença na veracidade da imagem, a expressão mostra-se cada vez mais presente. $\mathrm{O}$ autor alerta, porém que, por mais que a imagem fotográfica não reproduza o real e sim o produza, ela não pode ser desassociada de seu caráter documental.

Nesse ponto ele traça um histórico das funções da imagem na arte e descreve os papéis desempenhados pela fotografia alternadamente: o papel de refugo da arte (com o impressionismo), de paradigma da arte (com Marcel Duchamp), de ferramenta da arte (com Francis Bacon e Andy Warhol) e de vetor da arte (nas artes conceitual e corporal). A obra de Warhol afasta-se da pintura e critica a sociedade do espetáculo, do fetichismo da mercadoria. Já Moholy-Nagy foi um dos primeiros artistas a utilizar conscientemente a luz e a matéria fotográfica como material artístico. Essa evolução foi radical, pois a diferença entre o vetor e o material não é de grau, mas de natureza. Nos anos 20, as vanguardas como o dadaísmo e o surrealismo já utilizavam a fotografia, porém, foi apenas nos anos 80 que a fotografia tornou-se um dos principais materiais da arte: o fazer artístico foi ressignificado.

Em $A$ arte-fotografia, terceira parte do livro, o autor explica que a imagem fotográfica, como material, passou a se misturar com a arte. Christian Boltanski declarou pintar com a fotografia. Ele fez parte do movimento na contracorrente da concepção modernista, segundo a qual o artista deveria purificar sua arte de todos os elementos "emprestados".

Após a complexidade estética da arte modernista e a sofisticação teórica da arte conceitual, ocorreu uma espécie de recuo. As obras ficaram indiferentes à questão da essência, passaram da profundidade para a superfície, tratavam do banal, do cotidiano, da imperfeição. 
Em tempos de globalização os contatos se intensificam, os limites de deslocam. "A passagem de um mundo centralizado para um mundo de redes inaugura uma nova ordem visual que a fotografia não pode mais sustentar." (ROUILLÉ, 2009, p.157). Rouillé afirma que essas novas configurações se manifestam na arte: os materiais não são neutros e inertes, eles evoluem acompanhando condições técnicas, econômicas, estéticas e novos hábitos visuais do momento.

Artistas criam obras que criticam situações sociais e políticas. "A importância, a variedade e a renovação das questões políticas em numerosas obras da arte-fotografia já atestam sua implicação, forte e nova, no trajeto do mundo." (ROUILLÉ, 2009, p.390). O espectador passa a ter papel ativo e interage com a arte-fotografia, que provém de uma ampla abertura temática e da renovação das visibilidades. Ocorre uma reconfiguração de fronteiras entre fotografia, moda e arte contemporânea.

O autor ressalta que atualmente a imagem fotográfica está em crise: "Nascida na era do ferro e do carvão, responde mal às condições da sociedade da informação.” (ROUILLÉ, 2009, p.135). Ele critica a imagem digital afirmando que ela é composta de símbolos matemáticos gerados por linguagem de programação e não é mais acompanhada por uma troca energética, um sistema químico negativo-positivo, um elo físico, o processo de sensibilização dos sais de prata. Essa passagem atinge a própria natureza da fotografia e o regime de verdade que a sustentava. Seu caráter variável e flexível faz com fique sob suspeita. Instala-se outro regime de verdade, outras práticas estéticas, novas configurações materiais e mudam as relações das imagens com o tempo.

Para Rouillé, a fotografia tem sido mal interpretada e reduzida. Ele lembra que a imagem fotográfica transitou por diferentes caminhos e recebeu diversos status, sendo aceita na contemporaneidade como material independente da arte. Assim, tece uma profunda reflexão sobre a imagem fotográfica desde seus primórdios. No final do livro afirma que o referente já não adere mais (algum dia aderiu?) e que as imagens, na era digital, são amputadas de sua origem material, passando do 
regime de molde para o regime da modulação. Pela ousadia de questionar verdades consagradas, defender veemente suas posições e pela abrangência de suas reflexões e conexões, o livro torna-se um importante instrumento de pesquisa e sua leitura é indispensável para pensadores da fotografia, da arte e da sociedade contemporânea. 